\title{
Human papillomavirus infection in honduran women with normal cytology
}

\author{
N. Tábora · J. M. J. E. Bakkers · W. G. V. Quint • \\ L. F. A. G. Massuger · J. A. Matute \\ W. J. G. Melchers $\cdot$ A. Ferrera
}

Received: 10 February 2008/Accepted: 29 July 2009/Published online: 15 August 2009

(c) The Author(s) 2009. This article is published with open access at Springerlink.com

\begin{abstract}
Objective This study was aimed at estimating type-specific HPV prevalence and its cofactors among Honduran women with normal cytology in order to provide valuable information to health policymakers about the epidemiology of this important sexually transmitted infection.

Methods A total of 591 women with normal cytology from Tegucigalpa, Honduras were interviewed and tested for HPV using the SPF10 LiPA25. A structured epidemiological questionnaire was administered to each woman.

Results The overall HPV prevalence was $51 \%$. Twentythree types of HPV were detected; HPV 16, 51, 31, 18, and 11 were the most common. The highest prevalence of cancer associated HPV types (15.0\%) was found in the women less than 35 years. Besides the association with age, the main independent predictors of HPV infection were the lifetime number of sexual partners and having a
\end{abstract}

N. Tábora · A. Ferrera $(\bowtie)$

Department of Microbiology, Universidad Nacional Autónoma de Honduras (UNAH), Tegucigalpa, Honduras

e-mail: annabelle@amnettgu.com; f_annabelle@ hotmail.com

J. M. J. E. Bakkers · W. J. G. Melchers

Department of Medical Microbiology, Radboud University

Nijmegen Medical Centre, Nijmegen, The Netherlands

W. G. V. Quint

DDL Diagnostic Laboratory, Voorburg, The Netherlands

L. F. A. G. Massuger

Department of Obstetrics and Gynaecology, Radboud University

Nijmegen Medical Centre, Nijmegen, The Netherlands

J. A. Matute

CIENSA (Center for Research in Nutrition and Health),

Guatemala City, Guatemala low socioeconomic status and less than 5 previous Pap smears.

Conclusions In the population studied, there was a broad diversity of HPV infections, with high-risk types being the most common types detected. The establishment of a wellcharacterized population with regard to the community prevalence of type-specific HPV infection will provide a valuable baseline for monitoring population effectiveness of an HPV vaccine.

Keywords HPV · Honduras - Normal cytology · Risk factors

\section{Introduction}

Carcinoma of the cervix is the most common type of cancer in the developing world and the leading cause of death from cancer among women. The estimated new cervical cancer cases per year is 500,000 [1], $80 \%$ of which is occurring in the developing countries [2]. In Central and South America, the incidence rate is about 5 times as high as in Western Europe [3]. In Honduras, cancer of the cervix is a major public health problem and also has the highest mortality rates due to cancer among women with a cervical cancer age standardized rate of 30.6/100,000 inhabitants [4].

There is overwhelming data from multiple epidemiologic and laboratory studies demonstrating the central etiologic role of human papillomavirus (HPV) in cervical cancer [5-10].

It is necessary to understand the global burden of HPV infections in order to establish effective prevention strategies such as improved screening programs, public health education, and vaccines [11]. In this context, surveys to 
determine HPV prevalence in different age groups and circulating genotypes in the population are needed to understand the wide variations in the incidence of cervical cancer in populations worldwide. These will contribute to establish the proportion of women that could be effectively protected by vaccination.

Despite the high incidence of cervical cancer reported from Honduras, population-based studies on the HPV prevalence and genotype distribution are scarce [12, 13]. It is of fundamental importance to get insight into the development of this disease in order to design effective strategies to treat and prevent cervical carcinoma and its related mortality and morbidity.

This study was aimed at determining type-specific HPV prevalence and its cofactors among Honduran women with normal cytology in order to provide valuable information to health policymakers about the epidemiology of this sexually transmitted infection.

\section{Methods}

Study population and collection of specimens

The study population included a sample of 591 women, randomly selected, attending a communal cervical cancer screening centers and family planning clinics in lowmedium socioeconomic settings in Tegucigalpa, the capital city of Honduras. In general, women may be referred for screening by their physicians or request screening on their own accord. Eligible women were those between 18 and 65 years of age, identified as being resident for at least 6 months in Tegucigalpa, without a history of preneoplasic or neoplasic lesions of the cervix, conization or hysterectomy, not currently pregnant, who were willing to participate and who signed an informed consent form.

The nature of the study was explained to the patients by trained medical staff

A thorough physical examination was performed, and a structured epidemiological questionnaire was administered to each woman. Questions pertained to sociodemographic variables like age, occupation, education level, smoking; contraceptive use, previous cervical smear history and exposure to wood smoke and also questions regarding sexual behavior to gain insight into risk factors for acquiring HPV were asked. The interviews lasted approximately $15 \mathrm{~min}$. Assurance of confidentiality was obtained by gathering some of the information in two different questions and at the end of each interview the interviewer could address if the information given by the patient was reliable and if she appeared confident.
The study was reviewed and approved by the correspondent ethical committee

Five women did no consent to participate in the study $(<1 \%)$

An Ayre spatula was used to obtain a cervical smear, which was immediately fixed for cytological examination. Following the Pap collection, additional material was obtained from the cervix for HPV analysis and placed in $5 \mathrm{~mL}$ sterile phosphate-buffered saline (PBS, $0.82 \%(\mathrm{w} / \mathrm{v})$; $\mathrm{NaCl}, 0.19 \%$ (w/v); $\mathrm{Na}_{2} \mathrm{HPO}_{4} 2 \mathrm{H}_{2} \mathrm{O}, 0.03 \%$ (w/v); $\mathrm{NaH}_{2}$ $\mathrm{PO}_{4} 2 \mathrm{H}_{2} \mathrm{O}$, adjusted to $\mathrm{pH} 7.4$ with $\left.\mathrm{HCL} 1 \mathrm{M}\right) 0.005 \%$ thimerosal. Upon arrival in the laboratory, cells were vortexed, centrifuged for $10 \mathrm{~min}$ at $4,500 \mathrm{rpm}$, then resuspended in $1 \mathrm{~mL}$ of PBS and centrifuged again for $10 \mathrm{~min}$ at $4,500 \mathrm{rpm}$, resuspended in $0.5 \mathrm{~mL}$ of PBS and stored at $-20^{\circ} \mathrm{C}$ for further analysis. Extreme caution was taken to prevent crosscontamination of specimens. Pap smears were all reviewed by the same pathologist. Six women were excluded due to abnormal cytology results (1\%).

HPV DNA detection

\section{DNA extraction and HPV-PCR assay}

DNA extraction from the cervical cells was performed according to the Boom method as previously described [14]. Two hundred microliters of material was isolated and resuspended in a final volume of $100 \mu \mathrm{L}$; an extraction control consisting of nuclease free water was placed after every 5th sample. About $10 \mu \mathrm{L}$ of sample DNA or control were used for each of the various PCR analyses.

All samples were prescreened with the $\beta$-globin primers $\mathrm{PCO} 3 / \mathrm{PCO} 5$ to assess sample integrity.

All work was performed in a laminar flow hood in a dedicated room free from plasmid DNA.

\section{HPV SPF ${ }_{10}$ Line Blot ${ }_{25}$ assay}

(i) PCR amplification of HPV DNA. Broad-spectrum HPV DNA amplification was performed using a short PCR fragment assay (HPV SPF 10 Line Blot 25 assay Labo Biomedical products B. V. Rijswijk, The Netherlands). This assay amplifies a 65-bp fragment of the L1 open reading frame, and allows detection of at least 43 different HPV types. $\mathrm{SPF}_{10}$ PCR system was performed in a final reaction volume of $50 \mu \mathrm{L}$, containing $10 \mu \mathrm{L}$ of the isolated DNA sample and $40 \mu \mathrm{L}$ PCR mix, containing $10 \mathrm{mmol} / \mathrm{L}$ TrisHCL (pH 9.0), $50 \mathrm{mmol} / \mathrm{L} \mathrm{KCL}, 2.0 \mathrm{mmol} / \mathrm{L} \mathrm{MgCl}_{2}, 0.1 \%$ Triton X-100, $0.01 \%$ gelatine, $200 \mu \mathrm{mol} / \mathrm{L}$ of each deoxynucleoside triphosphate (dATP, dCTP, dGTP, and dTTP), 15 pmol each of the forward and reverse primers 
tagged with biotin at the $5^{\prime}$ end, and 1.5 units of AmpliTaq Gold $^{\circledR}$ (Applied Biosystems, Foster City, CA, USA). Activation of AmpliTaq Gold for $9 \mathrm{~min}$ at $94^{\circ} \mathrm{C}$ was followed by 40 cycles of $30 \mathrm{~s}$ at $94^{\circ} \mathrm{C}, 45 \mathrm{~s}$ at $52^{\circ} \mathrm{C}$ and $45 \mathrm{~s}$ at $72^{\circ} \mathrm{C}$, with a final extension of $5 \mathrm{~min}$ at $72^{\circ} \mathrm{C}$. Appropriate negative and positive controls were used to monitor the performance of the PCR method in each experiment. To avoid contamination by PCR products, sample preparation and the amplification reaction were all performed in separate rooms.

(ii) HPV detection by DEIA. The presence of HPV DNA was determined by hybridization of $\mathrm{SPF}_{10}$ amplimers to a mixture of general HPV probes recognizing a broad range of high-risk, low-risk and possible high-risk HPV genotypes in a microtiter plate format, as described previously. All HPV DNA positive samples (by $\mathrm{SPF}_{10}$ DEIA) were genotyped using the HPV $\mathrm{SPF}_{10}$ Line Blot $_{25}$ genotyping assays.

(iii) HPV genotyping by reverse hybridization using the HPV SPF 10 Line Blot 25 genotyping system. The 28 oligonucleotide probes which recognize 25 different types were tailed with poly(dT) and immobilized as parallel lines to membrane strips (Labo Bio-medical products B. V. Rijswijk, The Netherlands). The HPV genotyping assay was performed as described previously. The LiPA strips were manually interpreted using the provided reference guide.

The samples that tested positive using the DNA Enzyme Immuno Assay but showed no results on the LiPA strip were considered to be HPV X-type, i.e., genotypes not present on the LiPA strip.

To evaluate performance and reproducibility of the analysis, a quality control program from DDL was performed.

\section{Data analysis}

Statistical analyses were performed using the programs EpiInfo 6.02 (CDC) statistical program, Excell and LogXact version 4 (Cytel, Cambridge Ma).

Univariate statistics were calculated for all variables. Any $p$ value less than 0.05 was considered significant. Odds ratios (ORs) and 95\% confidence intervals (CIs) were obtained from multiple logistic regression models to evaluate the association between HPV infections and risk factors. Variables found to be significantly related to HPV infection by univariate analyses were entered into a multiple logistic regression model. We adjusted for age using five groups contrasted as dummy variables 18-24, 25-34, 35-44, 45-54, and 55-65) and for HPV infection status (only low risk types and any high risk types). We investigated the potential association with education, socioeconomic status, exposure to wood smoke, history of pregnancy, parity, age at first intercourse, lifetime number of sexual partners, number of previous screens, time since last Pap smear, history of sexually transmitted diseases, and occurrence of other genital infections that could influence the development of SIL. The variables that remained in the final multivariate models were: age, women's education, socioeconomic status, time since last Pap smear, and number of sexual partners.

\section{Results}

Among the 591 women with normal cytology enrolled in this study, 29 were negative for the $\beta$-globin PCR and were eliminated from the study; from the remaining 562 samples, $289(51 \%)$ were positive for HPV DNA. Overall, single genotypes were found in $67 \%$ of the $289 \mathrm{HPV}$ positive women (36\% of the entire sample) and multiple genotypes were detected in $33 \%$ of the HPV positives women $(15.8 \%$ of total).

Twenty-three HPV types were ascertained; HPV 16 (25\%), HPV 18 (12\%), HPV 51 (10\%), HPV 31 (8\%), and HPV $11(8 \%)$ were the most common types identified (Fig. 1).

Figure 2 shows the age-specific prevalence of HPV detection. HPV DNA was detected in $58 \%$ of women aged less than 25 years, with prevalence decreasing in older women to a minimum of $30 \%$ among women older than 55 .

Overall of the $51 \%$ HPV positive women, $35.7 \%$ were infected with high risk (HR) types and $15.3 \%$ with low risk (LR) types only. Women who were infected with both HR/ LR types were grouped as HR types. HR HPV age-specific prevalence was highest among women below age 25 (46.5\%), and again lowest among women aged 55 or more years $(22.7 \%$; Fig. 3).

When considering all HPV types and all age groups combined, besides the association with age, we observed a trend for HPV infection and the lifetime number of sexual partners (Table 1). The only other factors that remained significant were having a low socioeconomic status (SES) and less than five previous Pap smears, and women who had six or more previous screens had a reduced risk of HPV infection. In HPV positive women, risk factors for detection of single and multiple HPV infections for all types were analyzed (Table 2). A total of 200 (69\%) of 289 HPV-positive women had a single infection, whereas 89 women $(31 \%)$ had multiple HPV type detected. For single HPV infection, the highest prevalence was found among women less than 25 years $(48.8 \%)$, whereas for multiple infections the highest percentage was observed in women between 25 and 34 years (19.3\%). Both single and multiple infections were associated with low socioeconomic status (SES) and with reporting more than one lifetime sexual partner. When analyzing the number of previous screens, an OR of 1.9, for women who had undergone cytological screening 6-10 month prior to the interview, was observed. 
Fig. 1 Prevalence of individual HPV types among Honduran women with normal cytology

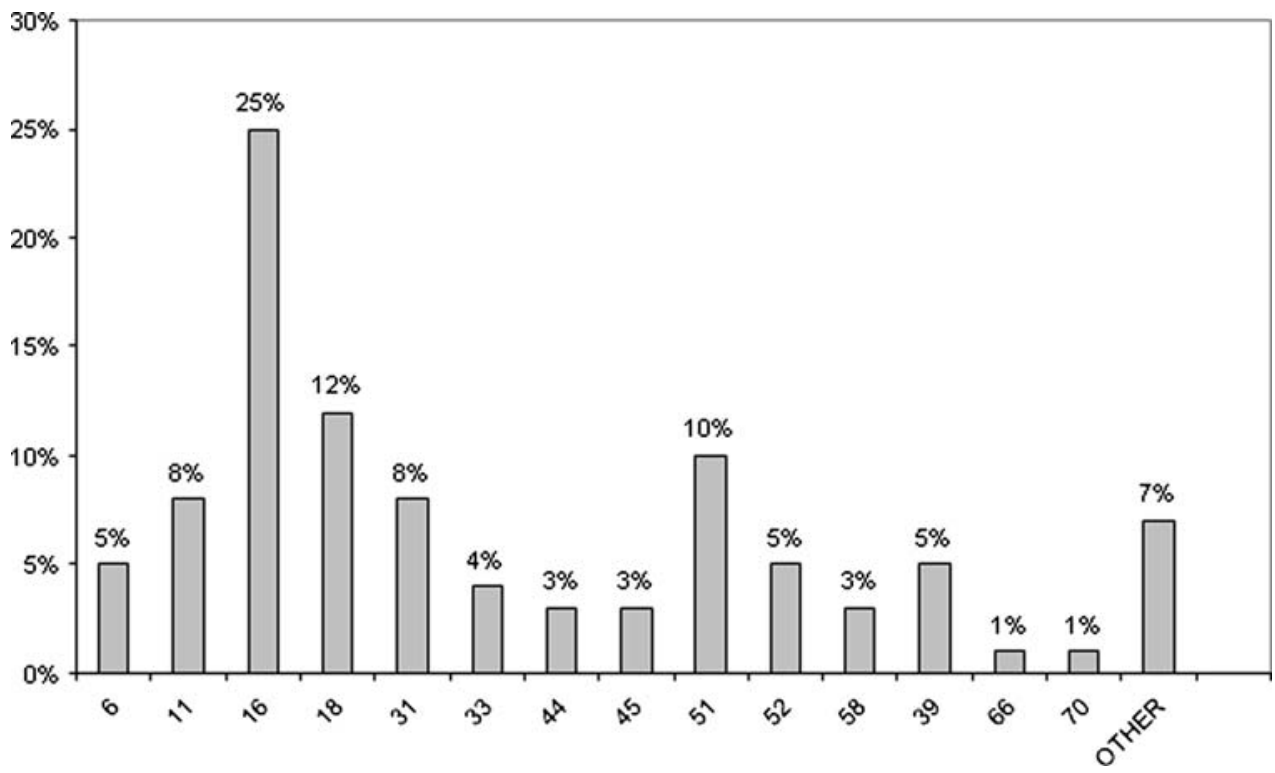

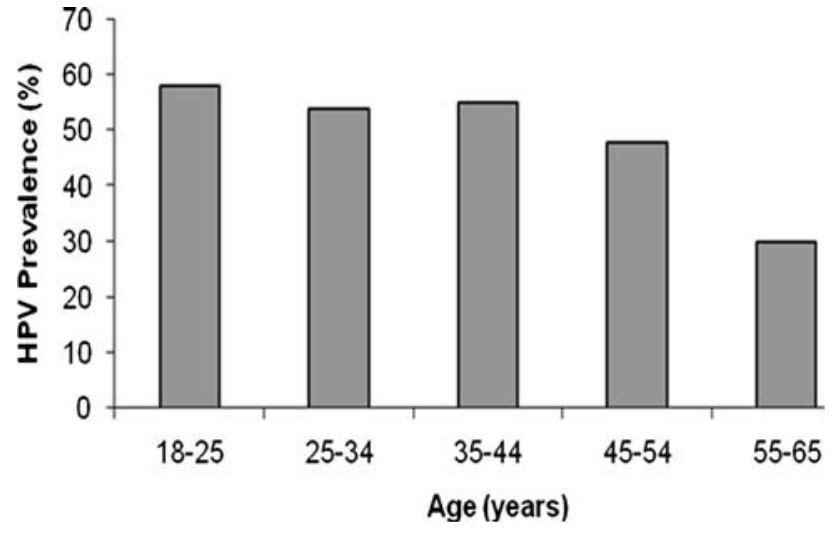

Fig. 2 HPV prevalence in Honduran women with normal cytology according to age

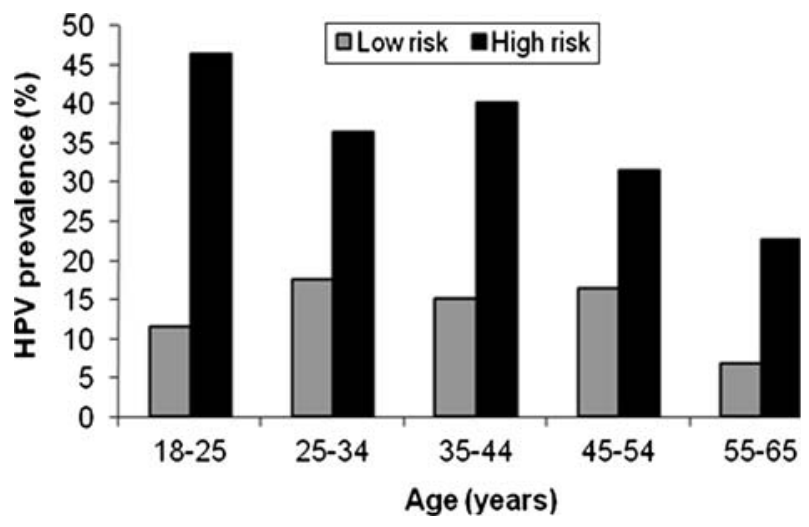

Fig. 3 Prevalence of high- and low-risk HPV detection among Honduran women

A stronger association was found in the women with multiple HPV infection that had the last Pap smear taken $0-5$ months before $(\mathrm{OR}=2.6)$.
When doing multivariate logistic regression analysis, a statistically significant association for HPV infection was ascertained for the women who had a low SES $(\mathrm{OR}=1.8$, $95 \% \mathrm{CI}=1.2-2.5)$.

Risk of HPV infection was reduced for women who were 45 years or older and had only one lifetime sexual partner $(\mathrm{OR}=0.7,95 \% \mathrm{CI}=0.5-1.0)$.

\section{Discussion}

In our survey, the prevalence of genital HPV infections in the studied population was very high $(51 \%)$ when compared to what has been reported internationally. It is higher than the prevalence found among women with normal cytology in several other Latin American countries: Costa Rica (16\%), Mexico (14.5\%), Colombia (14.9\%), and Chile (14.0\%) but similar to the one observed previously in Honduras (39\%) considering that in the present study a more sensitive PCR detection system was used [13, 15-18].

As it happens in most developing countries, in Honduras some cultural factors can be related to this high HPV prevalence, especially lack of education; early start of sexual activity; multiparity; and the prevalence of attitudes, misconceptions and beliefs that constrain people from discussing diseases of the genital tract. In most developing countries, access to health services is limited and screening for cervical cancer either is nonexistent or reaches few of the women who need it. A well-functioning health system, with the necessary equipment and trained providers, is essential for prevention activities, screening and diagnosis, linkages for follow-up and treatment, and palliative care. $[7,9,10,12,13,15]$. 
Table 1 Risk factors for HPV DNA detection among Honduran asymptomatic women

\begin{tabular}{|c|c|c|c|c|c|c|}
\hline & \multicolumn{2}{|c|}{ HPV positive (289) } & \multicolumn{2}{|c|}{ Low-risk HPV types } & \multicolumn{2}{|c|}{ High-risk HPV types } \\
\hline & $\%$ & OR & $\%$ & OR & $\%$ & OR \\
\hline \multicolumn{7}{|l|}{ Age (years) } \\
\hline$<25$ & 4.4 & 3.31 & 0.2 & 0.86 & 3.6 & 3.44 \\
\hline $25-34$ & 16.9 & 2.80 & 1.8 & 1.91 & 11.4 & 2.45 \\
\hline $35-44$ & 16.9 & 2.94 & 1.9 & 2.21 & 12.3 & 2.78 \\
\hline $45-54$ & 10.9 & 2.20 & 1.8 & 2.35 & 7.1 & 1.88 \\
\hline$>55$ & 2.3 & 1.00 & 0.4 & 1.00 & 1.8 & 1.00 \\
\hline \multicolumn{7}{|c|}{ Women's education (years) } \\
\hline$\geq 7$ & 19 & 1.00 & 4.7 & 1.00 & 15.8 & 1.00 \\
\hline$<7$ & 32 & $1.05(0.78-1.41)$ & 7.3 & $0.99(0.53-1.85)$ & 27.0 & $1.08(0.78-1.49)$ \\
\hline \multicolumn{7}{|c|}{ Socioeconomic status } \\
\hline Medium & 15.1 & 1.00 & 4.6 & 1.00 & 10.8 & 1.00 \\
\hline Low & 35.6 & $1.28(0.88-1.85)$ & 6.6 & $0.78(0.35-1.71)$ & 30.7 & $1.54(1.01-2.37)$ \\
\hline \multicolumn{7}{|c|}{ Exposure to wood smoke } \\
\hline No & 18.0 & 1.00 & 5.7 & 1.00 & 13.5 & 1.00 \\
\hline Yes & 35.2 & $0.79(0.53-1.16)$ & 6.4 & $0.45(0.21-0.99)$ & 30.6 & $0.91(0.59-1.40)$ \\
\hline \multicolumn{7}{|l|}{ Parity } \\
\hline $0-3$ & 33.7 & 1.00 & 7.8 & 1.00 & 26.7 & 1.00 \\
\hline$\geq 4$ & 19.1 & $0.72(0.50-1.05)$ & 4.8 & $0.79(0.35-1.74)$ & 17.8 & $0.84(0.56-1.27)$ \\
\hline \multicolumn{7}{|c|}{ Age at first intercourse } \\
\hline$>18$ & 22 & 1.00 & 6.0 & 1.00 & 16.0 & 1.00 \\
\hline$\leq 18$ & 31 & $0.95(0.66-1.36)$ & 6.0 & $0.67(0.31-1.45)$ & 27.3 & $1.14(0.76-1.71)$ \\
\hline \multicolumn{7}{|c|}{ Lifetime number of sexual partners } \\
\hline 1 & 23.7 & 1.00 & 6.7 & 1.00 & 20 & 1.00 \\
\hline$>1$ & 29.4 & $1.33(0.93-1.90)$ & 5.3 & $0.85(0.39-1.84)$ & 24.5 & $1.35(0.91-2.00)$ \\
\hline \multicolumn{7}{|c|}{ History of oral contraceptive use } \\
\hline No & 17.6 & 1.00 & 5.2 & 1.00 & 28.3 & 1.00 \\
\hline Yes & 32.7 & $1.05(0.73-1.52)$ & 9.2 & $2.20(1.01-4.79)$ & 13.5 & $0.93(0.62-1.41)$ \\
\hline \multicolumn{7}{|c|}{ No. previous screens } \\
\hline$>10$ & 6.2 & 1.00 & 2.5 & 1.00 & 3.5 & 1.00 \\
\hline $6-10$ & 17.8 & 1.04 & 4.4 & 0.62 & 14.2 & 1.47 \\
\hline $0-5$ & 29.2 & 1.42 & 5.5 & 0.64 & 26.2 & 2.27 \\
\hline \multicolumn{7}{|c|}{ Time since last Pap smear (months) } \\
\hline $0-11$ & 40 & 1.00 & 7.9 & 1.00 & 10.4 & 1.00 \\
\hline$\geq 12$ & 13.2 & $0.94(0.61-1.43)$ & 4.5 & $1.62(0.70-3.70)$ & 33.0 & $0.88(0.55-1.42)$ \\
\hline
\end{tabular}

Twenty-three different HPV types were detected in women in this study, which confirmed that there is great variability in the range of HPV types detected in exfoliated cervical cells at a population level in Latin America $[15,19,20]$.

As was seen in previous studies examining prevalence of various HPV types among large numbers of women presenting for reasons other than cervical neoplasia or known gynecologic problems, we found HPV 16 to be the most frequently detected HPV type, followed by HPV 18 , HPV 51, and HPV 31 [16, 21, 22]. In a Colombian-based study, HPV 16 was followed by HPV 58, 56, 18, and 51
[17]. In studies of Dutch, Mexican, and British women, the second most frequently detected HPV type was HPV 31, whereas among Brazilian women and women in the United States, HPV 53 was detected most frequently after HPV 16 [21]. In the Costa Rican population, oncogenic types 58, 51 , and 52 were also relatively abundant, followed by types 31 and 18 [15]. It seems that the family of HPV 50s is common in Latin America and should be considered when developing HPV vaccines tailored to this population.

A slightly higher prevalence of infection was found in women less than 25 years, with a strong predominance of cancer-associated HPV types and single HPV infections. 
Table 2 Risk factors for HPV DNA single and multiple detection among Honduran asymptomatic women

\begin{tabular}{|c|c|c|c|c|}
\hline & \multicolumn{2}{|c|}{ HPV single detection $(n=183)$} & \multicolumn{2}{|c|}{ HPV multiple detection $(n=93)$} \\
\hline & $\%$ & OR & $\%$ & OR \\
\hline \multicolumn{5}{|l|}{ Age (years) } \\
\hline$<25$ & 7.4 & 5.74 & 1.5 & 0.98 \\
\hline $25-34$ & 19.5 & 3.38 & 12.5 & 1.86 \\
\hline $35-44$ & 23.2 & 4.23 & 9.6 & 1.50 \\
\hline $45-54$ & 15.1 & 3.21 & 6.6 & 1.21 \\
\hline$>55$ & 2.2 & 1.00 & 2.6 & 1.00 \\
\hline \multicolumn{5}{|c|}{ Women's education (years) } \\
\hline$\geq 7$ & 15 & 1.00 & 9.0 & 1.00 \\
\hline$<7$ & 25.5 & $1.07(0.77-1.49)$ & 16.4 & $1.14(0.75-1.75)$ \\
\hline \multicolumn{5}{|c|}{ Socioeconomic status } \\
\hline Medium & 10.6 & 1.00 & 8.0 & 1.00 \\
\hline Low & 28.6 & $1.47(0.95-2.28)$ & 17.2 & $1.16(0.68-1.99)$ \\
\hline \multicolumn{5}{|c|}{ Exposure to wood smoke } \\
\hline No & 14.6 & 1.00 & 8.2 & 1.00 \\
\hline Yes & 27.1 & $0.74(0.48-1.15)$ & 18.8 & $0.92(0.53-1.60)$ \\
\hline \multicolumn{5}{|l|}{ Parity } \\
\hline $0-3$ & 26.2 & 1.00 & 16.1 & 1.00 \\
\hline$\geq 4$ & 16.0 & $0.78(0.51-1.19)$ & 11.5 & $0.90(0.54-1.53)$ \\
\hline \multicolumn{5}{|c|}{ Age at first intercourse } \\
\hline$>18$ & 18.0 & 1.00 & 9.8 & 1.00 \\
\hline$\leq 18$ & 23.6 & $0.88(0.58-1.33)$ & 16.9 & $1.16(0.68-1.96)$ \\
\hline \multicolumn{5}{|c|}{ Lifetime number of sexual partners } \\
\hline 1 & 19.0 & 1.00 & 11.4 & 1.00 \\
\hline$>1$ & 22.5 & $1.27(0.85-1.91)$ & 15.5 & $1.46(0.88-2.44)$ \\
\hline \multicolumn{5}{|c|}{ History of oral contraceptive use } \\
\hline No & 24.3 & 1.00 & 17.0 & 1.00 \\
\hline Yes & 15.0 & $1.20(0.79-1.82)$ & 8.2 & $0.95(0.55-1.61)$ \\
\hline \multicolumn{5}{|c|}{ No. previous screens } \\
\hline$>10$ & 9.2 & 1.00 & 2.3 & 1.00 \\
\hline $6-10$ & 21.8 & 0.86 & 11.9 & 1.87 \\
\hline $0-5$ & 34.9 & 1.14 & 19.9 & 2.61 \\
\hline \multicolumn{5}{|c|}{ Time since last Pap smear (months) } \\
\hline $0-11$ & 31.0 & 1.00 & 20.8 & 1.00 \\
\hline$\geq 12$ & 10.5 & $0.96(0.59-1.55)$ & 6.5 & $0.89(0.48-1.63)$ \\
\hline
\end{tabular}

HPV detection decreases among the women over 55 years (Fig. 2). This result has been interpreted as an indicator of the sexual transmission as it coincides with the initiation of sexual activity. It is a known fact that HPV prevalence decreases with age, as has been shown in several studies of younger women [23-25].

We did not find a second peak of HPV after 55 years of age as observed in a cohort study being conducted in Guanacaste, Costa Rica [15], in Morelos, Mexico [16], Our results are well in accordance with Cuschiere et al. [26], who did not find a second peak in peri-menopausal women in a survey conducted in Edinburgh and with Beby-Defaux et al.
[27] in women who attended a Health Examination Center of the French social security; they observed that HPV prevalence gradually decreased with age. Differences in HPV DNA prevalence found in different studies, overall and by age, may be partly accounted for by differences in cohort effects and PCR methods used for HPV detection. In our study, it could also be that the group of women over 55 years was too small (13 women) to exhibit a second peak.

The presence of multiple infections (33\%) was higher than previously observed among control subjects in the IARC studies done in the Philippines (14.3\%), [28] Thailand (9.8\%) [29], Morocco (5.3\%) [30], Paraguay (16.7\%) [22], 
and The Netherlands (28\%) [21], but lower than in a population-based study from Costa Rica (39\%) [15] and similar to the results from a study done in Colombia (29.7\%) [17]. The extent and importance of multiple HR-HPV infections in the progression of cervical neoplasia and its management remain unknown. Some studies have described multiple HR-HPV infections to be most prevalent in young women and to be more frequent in low grade than in high grade cervical neoplasia, which could reflect common sexual transmission of multiple HR-HPV [22, 26, 31, 32]. On the other hand, Bachtiary et al. [33] demonstrated that the presence of multiple HPV types is associated with poor response and with reduced survival in cervical cancer patients who receive radiotherapy as the primary treatment.

We explored risk factors for acquiring HPV infection and found that the number of sexual partners was weakly related to HPV infection, in contrast to what has been demonstrated in previous studies [34-36] and not well in accordance with data described before in Honduran women [37]. This could be the result of bias, since for cultural reasons women might not tell the real number of sexual partners or it could be explained by the predominance of "male role" in the transmission of HPV infections to women committed to one sexual partner. In this context, a woman's risk of cervical cancer may depend less on her own sexual behavior than on that of her husband or other male partners. Unfortunately, no information was available on the sexual behavior of the partners in our study population.

In the present study there was no association between HPV infection and the use of wood for cooking, considering that bias could have been introduced when they answered the question and the time of exposure to wood smoke was not measured. On the other hand, Ferrera et al. [37] found in a case-control study performed in Honduran women, a strong association between the use of wood as cooking fuel for many years and cervical cancer even after adjustment for education, strongly suggesting that exposure to wood smoke is not just an indicator of SES, but inclined them to believe that there could be a biologic effect.

Our results also showed that there was an association of HPV infection with number of previous screens, especially for multiple infections, in which women who had less than five previous screens had a two times higher risk of HPV infection than women who had more than 10 previous screens, supporting the preponderant role of cervical screening in the effective control of cervical cancer. This is in complete concordance with previous findings in Honduran women in a case-control study; cytological screening conferred a protective effect [13]. Prospective studies are required to assess the impact of multiple HR-HPV infections on neoplastic progression.

There are limitations in the design of the study; one of them is the small sample size, especially in women over
55 years of age. As a health care center-based study, there is a potential bias related to the selection of the study subjects, as they were primarily seeking cervical cancer screening services. It would be necessary to compare some of the variables, like the education level of women participating in the study with women in the general population to see how representative the sample of women participating in the study is of the general population.

The recent approval by the US FDA and the European EMEA of an HPV vaccine to prevent high-risk HPV infection and development of cervical cancer represents a major landmark to eliminate the suffering and death due to cancer, reduce the need for costly medical procedures and provide both women and communities throughout the world with substantial benefits. HPV 16-18 vaccination will prevent HPV 16-18 incident infection, and subsequently decrease in $90 \%$ the frequency of abnormal Pap attributable to these types and in about 50\% overall abnormal Pap [38]. Besides, HPV vaccination will reduce the number of women who require colposcopy, biopsy, and cervical treatment for precancerous cervical lesions [39].

To maximize the cost-effectiveness of a HPV vaccination programmes, it is important to understand the distribution of the major HPV types in various geographic regions. The results emanating from this research may assist the public health authorities in planning prophylactic and therapeutic strategies to prevent cervical cancer, including HPV diagnosis and rational vaccine strategies. The establishment of a well-characterized population with regard to the community prevalence of type-specific HPV infection will provide a valuable baseline for monitoring population effectiveness of an HPV vaccine.

Acknowledgments This study was supported by The Netherlands Foundation for the Advancement of Tropical Research (WOTRO number WB 92-215).

Open Access This article is distributed under the terms of the Creative Commons Attribution Noncommercial License which permits any noncommercial use, distribution, and reproduction in any medium, provided the original author(s) and source are credited.

\section{References}

1. Krishnamerthis SV, Gajalakshmi CK, Suaminathan R, Ravichandran K (2000) Epidemiology of cancer of the cervix: global and national perspective. J Indian Med Assoc 98(2):49-52

2. Franco EL, Duarte-Franco E, Ferenczy A (2001) Cervical cancer: epidemiology, prevention and the role of human papillomavirus infection. CMJA 164(7):1017-1025

3. Arossi S, Sankaranarayanan R, Parkin DM (2003) Incidence and mortality of cervical cancer in Latin America. Salud Publica Mex 45:306-314. doi:10.1590/S0036-36342003000900004

4. Ferlay J, Bray F, Pisani P, Parkin DM (2004) GLOBOCAN 2002: cancer incidence, mortality and prevalence worldwide. IARC Press, Lyon Version 2.0. IARC Cancer Base No. 5 
5. Bosch FX, Manos MM, Muñoz N et al (1995) Prevalence of human papillomavirus in cervical cancer: a world-wide perspective. J Natl Cancer Inst 87(11):796-802. doi:10.1093/jnci/87.11.796

6. Andersson S, Rylander E, Larsson B, Strand A, Silfversvard C, Wilander E (2001) The role of human papillomavirus in cervical adenocarcinoma carcinogenesis. Eur J Cancer 37:246-250. doi: 10.1016/S0959-8049(00)00376-2

7. Cuschiere KS, Cubie HA, Whitley MW et al (2004) Multiple high risk HPV infections are common in cervical neoplasia and young women in a cervical screening population. J Clin Pathol 57(1):68-72. doi:10.1136/jcp.57.1.68

8. Muñoz N, Bosch FX, de Sanjosé S, Shah KV (1994) The role of HPV in the etiology of cervical cancer. Mutat Res 305(2):293301. doi:10.1016/0027-5107(94)90249-6

9. Franco EL, Villa LL, Sobrinho JP et al (1999) Epidemiology of acquisition and clearance of cervical human papillomavirus infection in women from a high-risk area for cervical cancer. J Infect Dis 180:1415-1423. doi:10.1086/315086

10. Reeves WC, Brinton LA, García M et al (1989) Human papillomavirus infection and cervical cancer in Latin America. N Engl J Med 320(22):1437-1441

11. Sellors JW, Mahony JB, Kaczorowski J et al (2000) Prevalence and predictors of human papillomavirus infection in women in Ontario, Canada. Survey of HPV in Ontario Women (SHOW) Group. CMAJ 163(5):535-538

12. Melchers W, Ferrera A, Willemse D et al (1994) Human papillomavirus and cervical cancer in Honduran women. Am J Trop Med Hyg 50:137-142

13. Ferrera A, Velema JP, Figueroa M (1999) Human papillomavirus infection, cervical dysplasia and invasive cervical cancer in Honduras: a case-control study. Int J Cancer 82:799-803. doi: 10.1002/(SICI)1097-0215(19990909)82:6<799::AID-IJC5>3.0. $\mathrm{CO} ; 2-5$

14. Boom R, Sol CJA, Salimans MM, Jansen CL, van Wetheim PME, van der Noordaa J (1990) Rapid and simple method for purification of nucleic acids. J Clin Microbiol 28:495-503

15. Herrero R, Hildesheim A, Bratti C (2000) A population-based study of all grades of cervical neoplasia in rural Costa Rica. J Natl Cancer Inst 92(6):464-473. doi:10.1093/jnci/92.6.464

16. Lazcano E, Herrero R, Muñoz N (2001) Epidemiology of HPV infection among Mexican women with normal cervical cytology. Int J Cancer 91(3):412-420. doi:10.1002/1097-0215(20010201) 91:3<412::AID-IJC1071>3.0.CO;2-M

17. Molano M, Posso H, Weiderpass E et al (2002) Prevalence and determinants of HPV infection among Colombian women with normal cytology. Br J Cancer 87(3):324-333. doi:10.1038/sj.bjc. 6600442

18. Ferreccio C, Prado RB, Luzoro AV et al (2004) Population-based prevalence and age distribution of human papillomavirus among women in Santiago, Chile. Cancer Epidemiol Biomarkers Prev 13(12):2271-2276

19. Muñoz N (2000) Human papillomavirus and cancer: the epidemiological evidence. J Clin Virol 19(1-2):1-5. doi:10.1016/S13 86-6532(00)00125-6

20. Deluca GD, Lucer RH, Martin de Civetta MT et al (2004) Human papillomavirus genotypes in women with cervical cytological abnormalities from an area with high incidence of cervical cancer. Rev Inst Med Trop Sao Paulo 46(1):9-12. doi:10.1590/S00 36-46652004000100002

21. Jacobs MV, Walboomers JMM, Snijders PJF, Voorhorst FJ, Daalmeijer NF, Meijer CJLM (2000) Age-related distribution patterns of 37 mucosotropic HPV types in women with cytologically normal cervical smears: decreased high/low risk ratio at older age. Int J Cancer 87(2):221-227. doi:10.1002/1097-0215 (20000715)87:2<221::AID-IJC11>3.0.CO;2-2
22. Rolon PA, Smith JS, Muñoz N (2000) Human papillomavirus infection and invasive cervical cancer in Paraguay. Int $\mathrm{J}$ Cancer 85:486-491. doi:10.1002/(SICI)1097-0215(20000215)85:4<486 ::AID-IJC7>3.0.CO;2-S

23. Melkert PWJ, Hopman E, Van den rule AJC et al (1993) Prevalence of HPV in citomorphologically normal cervical smears, as determined by the polymerase chain reaction is age-dependent. Int J Cancer 53:919-923

24. Burk RD, Kelly P, Feldman J et al (1996) Declining prevalence of cervicovaginal human papillomavirus infection with age is independent of other risk factors. Sex Transm Dis 23:333-341

25. Kjaer S, Van Den Brule A, Bock J et al (1997) Determinants of human papillomavirus (HPV) infection in 1000 randomly chosen young Danish women with normal Pap smear: are there different risk profiles for oncogenic and nononcogenic types? Cancer Epidemiol Biomarkers Prev 6:799-805

26. Cuschieri KS, Cubie HA, Whitley MW et al (2004) Multiple high-risk HPV infections are common in cervical neoplasia and young women in a cervical screening population. J Clin Pathol 57(1):68-72. doi:10.1136/jcp.57.1.68

27. Beby-Defaux A, Bourgoin A, Ragot S et al (2004) Human papillomavirus infection of the cervix uteri in women attending a health examination center of the French social security. J Med Virol 73(2):262-268. doi:10.1002/jmv.20085

28. Ngelangel C, Muñoz N, Bosch FX et al (1998) Causes of cervical cancer in the Philippines: a case-control study. J Natl Cancer Inst 90(1):43-49. doi:10.1093/jnci/90.1.43

29. Chichareon S, Herrero R, Muñoz N et al (1998) Risk factors for cervical cancer in Thailand: a case-control study. J Natl Cancer Inst 90(1):50-57. doi:10.1093/jnci/90.1.50

30. Chaouki N, Bosch FX, Munoz N et al (1998) The viral origin of cervical cancer in Rabat, Morocco. Int J Cancer 75:546-554. doi: 10.1002/(SICI)1097-0215(19980209)75:4<546::AID-IJC9>3.0. $\mathrm{CO} ; 2-\mathrm{T}$

31. Peyton CL, Gravitt PE, Hunt WC et al (2001) Determinants of genital human papillomavirus detection in a US population. J Infect Dis 183(11):1554-1564. doi:10.1086/320696

32. Gargiulo F, De Francesco MA, Schreiber C (2007) Prevalence and distribution of single and multiple HPV infections in cytologically abnormal samples from Italian women. Virus Res 125(2):176-182. doi:10.1016/j.virusres.2006.12.017

33. Bachtiary B, Obermair A, Dreier B et al (2002) Impact of multiple HPV infection on response to treatment and survival in patients receiving radical radiotherapy for cervical cancer. Int $\mathbf{J}$ Cancer 102(3):237-243. doi:10.1002/ijc.10708

34. Ley C, Bauer HM, Reingold A et al (1991) Determinants of genital human papillomavirus infection in young women. J Natl Cancer Inst 83:997-1003. doi:10.1093/jnci/83.14.997

35. Bauer HM, Hildesheim A, Schiffman MH et al (1993) Determinants of genital human papillomavirus infection in low risk women in Portland, Oregon. Sex Transm Dis 20:274-278. doi: 10.1097/00007435-199309000-00007

36. Giuliano A, Papenfuss M, Schneider A, Nour M, Hatch K (1999) Risk factors for high-risk type human papillomavirus infection among Mexican-American women. Cancer Epidemiol Biomarkers Prev 8:615-620

37. Ferrera A, Velema JP, Figueroa M et al (2000) Co-factors related to the causal relationship between human papillomavirus and invasive cervical cancer in Honduras. Int J Epidemiol 29:817825. doi: $10.1093 / \mathrm{ije} / 29.5 .817$

38. Soper D (2006) Reducing the health burden of HPV infection through vaccination. Infect Dis Obstet Gynecol 2006:83084. doi: 10.1155/IDOG/2006/83084

39. Burd E (2003) Human Papillomavirus and cervical cancer. Clin Microbiol Rev 16(1):1-17. doi:10.1128/CMR.16.1.1-17.2003 